\title{
NEW FRESHWATER TRICLADS FROM TASMANIA (PLATYHEILMINTHES, TURBELLARIA)
}

\author{
by
}

IAN R. BALL \& TRAN THI VINH-HAO

Department of Biology, University of Waterloo, Ontario, Canada

and

\section{Institute of Taxonomic Zoology, University of Amsterdam, The Netherlands}

\begin{abstract}
Three new freshwater triclads are described from Tasmanian lakes. Two of these represent the first records of the genus Spatbula in Tasmania and the third belongs to the endemic genus Romankenkius. The taxonomic affinities of the species are discussed and keys to all the Tasmanian genera and species are provided. These keys are to be regarded as provisional since it is likely that there remain many planarian species to be discovered and described from Tasmania.
\end{abstract}

\section{INTRODUCTION}

Only three species of freshwater planarians, or triclads have hitherto been described from Tasmania (Ball, 1974b). Two of these belong to the endemic genus Romankenkius and the third, Cura pinguis, is a species widespread in Australia, New Zealand, and New Caledonia. The absence of any representatives of the genus Spatbula, the most diverse Notogaean genus, has been held to be a zoogeographical anomaly (Ball, 1977a) but it is here resolved by descriptions of two new species from the island. A third new species of the endemic genus Romankenkius is also described. Keys to the Tasmanian genera and species are provided so as to encourage and facilitate further work on the fauna of this interesting region. But caution must be exercised in attempting to fit newly discovered specimens into these provisional keys. For a group as old as the planarians a total of six Tasmanian species is a meagre one and in all probability there are many more species to be discovered.

\section{MATERIALS AND METHODS}

For the present study only preserved material was available and in all essentials the methods employed were those described in previous studies of Australian freshwater plana. rians (Ball, 1977a). Locality references refer to the Tasmanian Lands Department Tasmap Series. In the keys characters that usually require the preparation of serial sections are given in parentheses; often however, entire cleared specimens will suffice for the recognition of diagnostic characters.

\section{SYSTEMATIC DESCRIPTIONS}

\section{Family Dugesindae Ball, 1974a}

Key to the Tasmanian genera of freshwater planarians

1. Anterior margin with two auricular streaks and four pairs of sensory fossae; (testes reduced to one or two pairs; male atrium with radial muscle plates; penial papilla long and slender). . Cura (1 species, see Ball, 1974b) Anterior margin with one or two pairs of sensory fossae, and two ciliated pits (testes numerous and close-packed; male atrium normal; penis a stout cone or cylinder) . 2

2. Anterior ramus of intestine without preocellar diverticula (oviducts, with at most a tiny caudal branch, and shell glands enter a posterior diverticulum of the bursal canal) . . . . . . . . . . . . Romankenkius Anterior ramus of intestine with one or two pairs of preocellar diverticula (oviducts, with a long caudal branch, and shell glands enter the bursal canal directly) . . . . . . . . . . . . . . Spatbula

Genus Romankenkius Ball, 1974b

Key to the known Species of Romankenkius

1. Colour fawn with two dark longitudinal strips (testes extend to the copulatory apparatus) . R. bilineatus sp. nov. Uniformly and darkly pigmented (testes prepharyngeal)

2. (Testes dorsal; penis with prostatic vesicle) . . . . . . . . . . . . . . . . R. kenki Ball, 1974b (Testes ventral; penis without prostatic vesicle) . . . . . . . . . . . . R. pedderensis Ball, 1974b

Romankenkius bilineatus sp. nov. (figs. 1, 4, 5) Type material. - Tasmanian Museum and Art Gallery, Hobart. Holotype: sagittal sections on one slide (K847). Paratypes: sagittal sections on three slides (K848), sagittal sections on one slide (K849), transverse sections of an immature specimen on one slide (K850), frontal sections of an immature specimen on one slide (K865). 

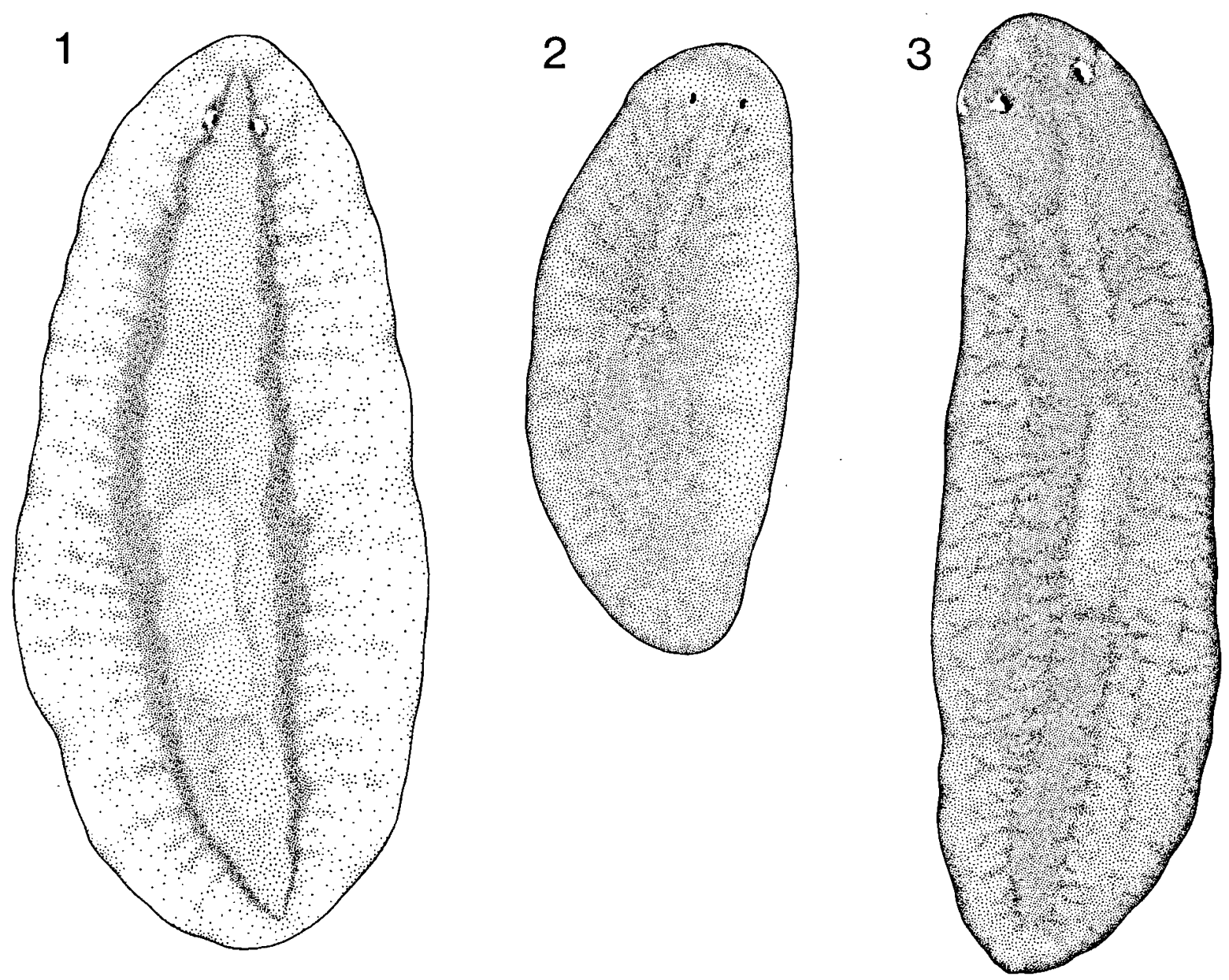

Figs. 1-3. External features of preserved specimens of three Tasmanian planarians: 1, Romankenkius bilineatus sp. nov.; 2, Spathula dittae sp. nov.; 3, Spatbula ochyra sp. nov. Scale lines $1 \mathrm{~mm}$.

Description. - Preserved specimens up to $5.5 \times$ $2.2 \mathrm{~mm}$. In life the animal is fawn or light brown with two longitudinal dark brown stripes that pass on each side of the mid-line and unite posteriorly and anteriorly. In preserved specimens the ground colour is white. The head is pointed, without tentacles, and the body broad and leaf-like with a rounded posterior end. There is one pair of eyes set close together and distant from the anterior margin, and one pair each of ciliated pits and sensory fossae. The anterior ramus of the intestine extends between the eyes without forming preocellar diverticula. The pharynx is large, its root being at about $55 \%$ of the body length and its tip at $70-75 \%$.
The copulatory apparatus is variable. The penis is always large, though only weakly muscular, and the bulb is usually rather shallow. The papilla takes the form of a wide cylinder and may be suspended vertically in the atrium (K847, K849, fig. 4) or be more normally disposed (K848, fig. 5). In the former case there is little space between the penis and the pharyngeal pocket and so the bursa lies displaced to the right side of the copulatory apparatus. The vasa deferentia enter the penis bulb separately from above, enlarging to form false seminal vesicles at the point of entry. There is no true seminal vesicle, or expanded bulbar cavity, and the wide ejaculatory duct opens centrally on the tip of the papilla. In two of the 
specimens there are glandular dilations of the proximal part of the ejaculatory duct (K848, K849). All the epithelia of the male apparatus are nucleate. The posterior wall of the male atrium is furnished with especially tall epithetial cells, or cushion cells, as is the facing epithelium of the penis papilla. The testes are very numerous, being situated both dorsally and ventrally to the intestine and extending from behind the ovaries to the level of the copulatory apparatus, often in a rather lateral position. They show a tendency to fusion.

The bursa copulatrix lies to the right of the copulatory apparatus (fig. 4) or it may lie between the penis and the pharynx (fig. 5) albeit still to the right of the mid-line. The bursal canal is an unusually wide duct that opens into the right side of the atrium near to the gonopore. Its nucleate epithelium is underlain by a thin layer of longitudinal muscle fibres and a thin layer of circular muscle fibres; the ectal region has an outer reinforcing layer of thin longitudinal fibres. Near to its junction with the atrium the bursal canal throws off a small diverticulum, either posteriorly or obliquely to the left. This diverticulum, which receives the separate openings of the unbranched oviducts, has a tall nucleate epithelium, but the surrounding musculature is much reduced. The shell glands open into this diverticulum and also into the neighbouring region of the bursal canal proper.

The paired ovaries are ventrally situated just behind the brain. Adpressed to these there may be a small clump of darkly staining vitelline cells on the antero-dorsal face of each. Otherwise the vitellaria are sparsely distributed throughout the body length, principally in the ventral half of the body.

Diagnosis. - The new species is easily distinguished from the two other species of the genus by its distinctive striped colour pattern and by the extension of the testes to the level of the bursa.

Distribution. - Romankenkius bilineatus has been confirmed only from the type locality which is Arthurs Lake in Tasmania. The specimens were collected by W. Fulton, 4 April 1977 (East Lake, South Arthurs Lake, grid ref. DP 964511) and 22 May 1977 (East Lake, North Arthurs Lake, grid ref. DP 951564). Fulton (in litt.) also reports this species from Great Lake and an outwardly similar species has been recorded by Leonard \& Timms (1974) from Lake Sorrell and Lake Crescent to the south-east. It may be that this species is widespread in Tasmania because we have received reports from $C$. Patterson and $H$. B. N. Hynes of the occurrence of a distinctly striped triclad in other Tasmanian waters. According to Fulton this species is found at depths of 7-15 meters on substrates ranging from sand to clay and silt.
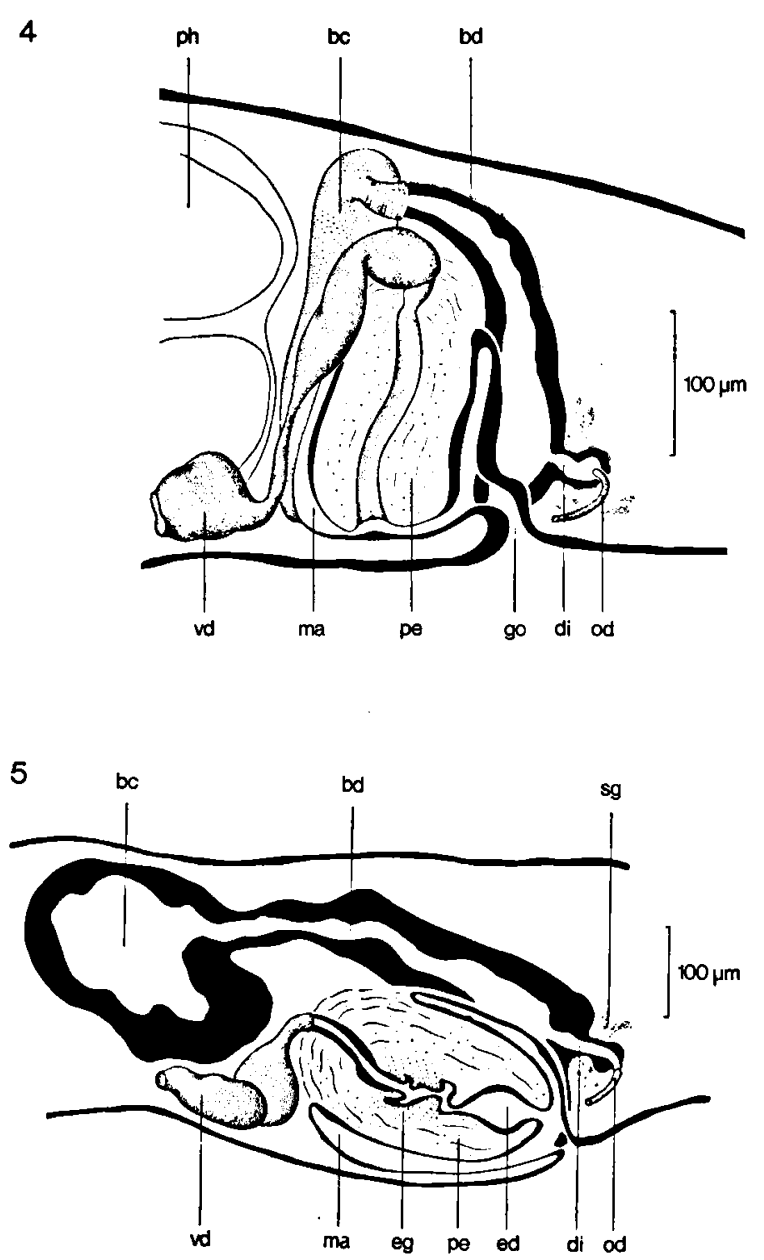

Figs. 4-5. Romankenkius bilineatus sp. nov., sagittal sections of the copulatory apparatus viewed from the left side. 4, Holotype (K847); 5, Paratype (K848). bc = bursa copulatrix; bd = bursal canal; di = diverticulum of bursal canal; ed - ejaculatory duct; eg = eosinophil glands; go = gonopore; $\mathrm{ma}=$ male atrium; od = left oviduct; pe = penis; ph = pharynx; sg = shell glands; vd = vas deferens. Fig. 4 has been reversed from the original slide. 
Etymology. - The specific epithet refers to the distinctive striped colour pattern of this species.

\section{DISCUSSION OF THE GENUS ROMANKENKIUS}

The genus Romankenkius was erected for two Tasmanian dugesiids, $R$. kenki and $R$. pedderensis, characterized by the opening of the oviducts and the shell glands into a posterior diverticulum of the bursal canal. This arrangement was interpreted as one manifestation of an evolutionary trend in aquatic planarians to the separation of the copulatory and glandular functions of the female genital canal, or vagina (Ball, 1974b, 1977c). Romankenkius bilineatus seems to be an intermediate form because the separation is not entirely complete in that whereas most of the shell glands empty into the diverticulum some empty into the bursal canal itself.

The new species differs from the other two species in the genus not only in the lesser development of the bursal canal diverticulum with its reduced musculature, but also in the extension of the testes beyond the pharyngeal root to the copulatory apparatus and in the absence of a ductus genito-intestinalis. The anatomy and histology of the genus has been considered in detail previously (Ball, 1974b) and in most other particulars, including the general asymmetry of the copulatory organs, the new species is in agreement with that analysis. One exception is particularly noteworthy however. The presence of a small clump of vitelline cells adpressed to the ovary is paralleled in a primitive Victorian species, Eviella bynesae Ball, 1977b. Other similarities between these two species are the broad leaf-like appearance and the fusion, partial in $R$. bilineatus and complete in E. bynesae, of the testicular follicles.

The variation in the copulatory apparatus of $R$. bilineatus (figs. 4,5 ) is quite remarkable and it may be that there are in fact two closely related, yet sympatric, species. It is also plausible to argue that the specimens with the vertically disposed penis and laterally displaced bursa (K847, K849) are more contracted than the specimen illustrated in fig. 5. But even in the latter specimen the bursa and its canal lie to the right of the mid-line and we are not convinced that all the differences can be explained as fixation artifacts. Our own material is insufficient, however, for a definitive solution to this puzzle and further analysis must be left to Australian zoologists with access to live material.

\section{Genus Spathula Nurse, 1950}

Key to the Tasmanian species of Spatbula

1. Anterior margin with one pair of sensory fossae; eyes symmetrical; (ejaculatory duct normal) . S. dittae sp. nov. Anterior margin with two pairs of sensory fossae; eyes wide apart; (ejaculatory duct wide, irregular, and eversible) . . . . . . . . . . S. ocbyra sp. nov.

Spathula dittae sp. nov. (figs. 2, 6)

Type material. - Department of Entomology and Invertebrate Zoology, Royal Ontario Museum, Toronto, Canada. Holotype: sagittal sections on one slide (ROM C139a). Paratype: sagittal sections on one slide (ROM C139b). Tasmanian Museum and Art Gallery, Hobart. Paratypes: three wholemounts on one slide (K845): sagittal sections on one slide (K846).

Description. - Maximum size $3.25 \times 1.0 \mathrm{~mm}$. Pigmented, dorsal surface a uniform light brown, ventral surface somewhat paler. The head is rounded, the body broad with parallel margins, the tail broad and blunt. There are two relatively large eyes set at a distance equal to that between the eyes and the frontal and lateral margins. There is one pair of ciliated pits and one pair of sensory fossae. The anterior ramus of the intestine extends between the eyes and forms two pairs of preocellar diverticula. The pharynx is relatively large, its root at $40 \%$ of the body length and its tip at $75 \%$; thus the tail of the worm is relatively short.

The copulatory complex is distinctive. The penis is large and consists of a well-developed, elongate and muscular bulb from which the broad plug-like papilla extends into the genital atrium. The vasa deferentia, showing little or no recurvature, enter the bulb separately from the sides and open into an expanded seminal vesicle of elongate shape that is lined with a tall nucleate epithelium. The wide ejaculatory duct travels straight through the penis papilla and opens slightly subterminally. The distal half of the penial papilla has reduced epithelial musculature and in the holotype it is separated from the proximal half by a lip or fold. The mesenchymal muscles of the papilla are well 


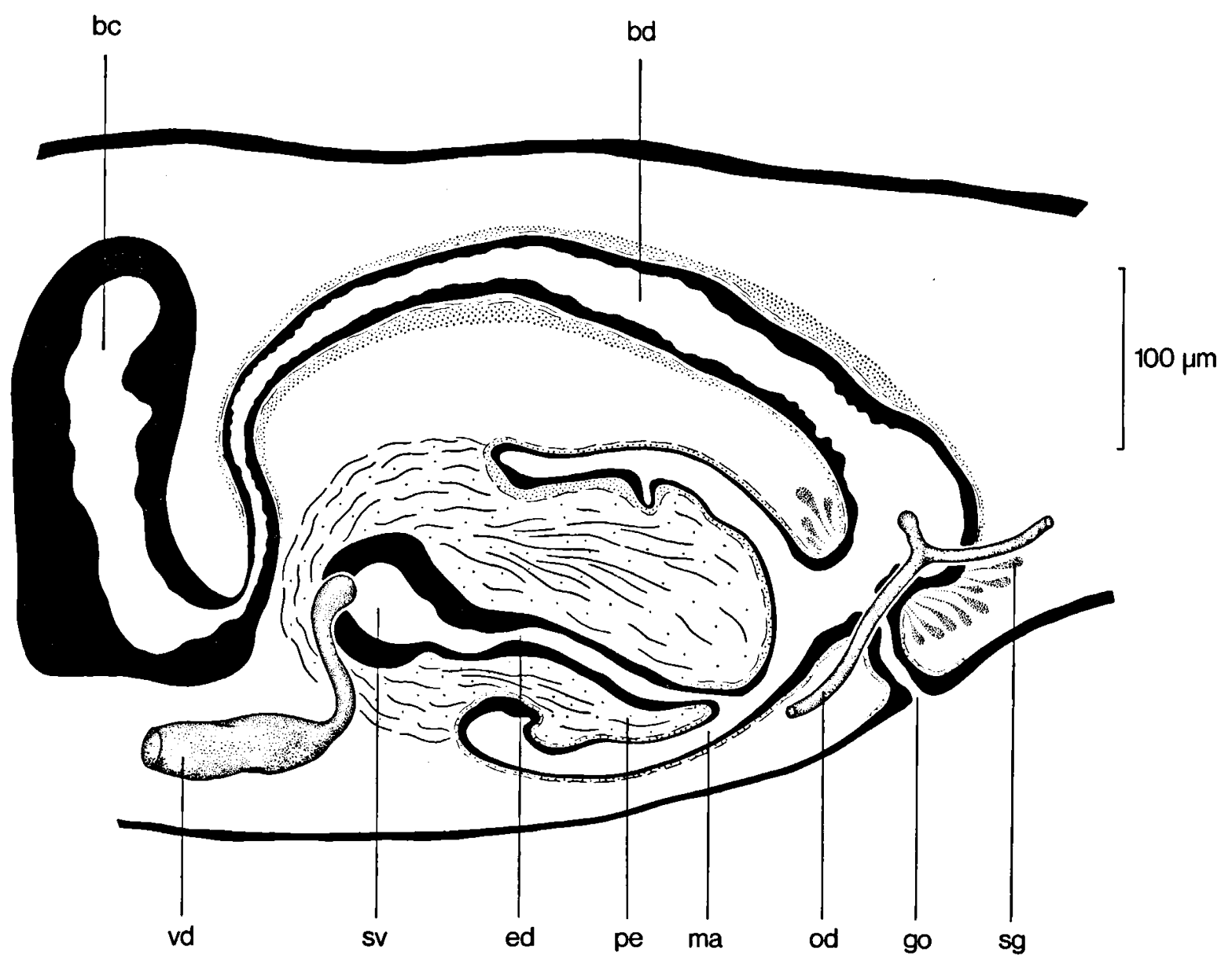

Fig. 6. Spatbula dittae sp. nov. Sagittal section through the copulatory apparatus of the holotype viewed from the left side. $\mathrm{bc}=$ bursa copulatrix; bd = bursal canal; ed = ejaculatory duct; go = gonopore; ma = male atrium; od = left oviduct; pe $=$ penis; $\mathbf{s g}=$ shell glands; $\mathbf{s v}=$ seminal vesicle; $\mathrm{vd}=$ vas deferens.

developed. The testes are very numerous, being packed closely together in the ventral regions of the body and distributed from just behind the ovaries to the level of the bursa.

The bursa copulatrix is a small sac lying between the penis and the pharyngeal pouch. On both the right and the left side it is in close contact with diverticula of the intestine but a true genitointestinal connection was not discerned. The bursal canal arises rather ventrally on the anterior face of the bursa, twists and ascends vertically, and then curves over the copulatory apparatus as an ever-widening duct that bends forward into the posterior wall of the atrium just above the gonopore. The nucleate cuboidal epithelium of the bursal canal is underlain by a thin layer of longi- tudinal muscles and a thicker layer of prominent circular fibres. The musculature is most strongly developed in the medial regions of the canal.

The paired ovaries are ventrally situated immediately behind the brain. The oviducts arise from the anterior face of each ovary and then curve laterally around them before travelling ventrally to the tail of the animal. However, as they pass the bursal canal each throws off a short branch that opens into the canal just before it opens into the atrium. Because of the relatively posterior position of the copulatory apparatus the caudal branches of the oviducts are relatively short. Shell glands empty into the bursal canal between the oviductal openings and the atrium. The vitellaria lie dorsally to the intestine, are most extensive in 
the middle regions of the body, and are sparse anteriorly and posteriorly. There are a few preovarian follicles.

Diagnosis. - In general habitus, in its possession of ventral testes distributed to the copulatory apparatus, and in the subterminal opening of the ejaculatory duct, Spathula dittae is most similar to S. foeni from Victoria (Ball, 1977a: 22). It may be distinguished from this species most easily by the strong musculature of the bursal canal and by the plug-like penis. The ventral opening of the bursal canal into the bursa is unusual as are the preocellar diverticula of the anterior ramus of the intestine, this latter feature being one shared only with the next species.

Distribution. - Known only from the type locality which is Lake St. Clair in Tasmania (grid ref. DP 345370). The specimens were collected on 18 March 1974 by Dr. G. Prince and forwarded to us by Dr. D. A. Hay of La Trobe University.

Etymology. - The specific epithet is for an outstanding friend, Dr. Dittie Rebel of Amsterdam.

Spathula ochyra sp. nov. (figs. $3,7,8,9,10$ )

Type material. - Tasmanian Museum and Art Gallery, Hobart. Holotype: sagittal sections on two slides (K866). Paratypes: sagittal sections on three slides (K867), sagittal sections of a specimen not fully mature on one slide (K868), frontal sections on one slide (K869), frontal sections of a specimen not fully mature on one slide (K870). In the last series the ribbons are arranged vertically, rather than horizontally as is our usual custom with frontal sections.

Description. - Preserved specimens up to $7 \times 2$ $\mathrm{mm}$. Dorsal surface dark-brown to black, pigment often blotchy, ventral surface paler. The head is rounded, the body broad. There are two eyes set wide apart, the distance between them exceeding the distance between each eye and its respective body margin. On the body margin just anterior to the eyes on each side there is a ciliated pit as found in all species of the genus. In the present species, however, this is an unusually deep sensory organ and in one specimen it forms a long tube running ventro-caudad almost to the plane of the eye itself. Between the ciliated pits and the anterior tip of the margin there are sensory fossae, two on each side. The anterior ramus of the intestine extends between the eyes and forms two pairs of preocellar diverticula. The pharynx is about one fifth of the body length, its root being a little less than halfway down the body.

The copulatory complex is unusual in the structure of the male apparatus. The penis is large and consists of an elongate and muscular bulb and a broad, blunt papilla that projects into the male atrium. The vasa deferentia, which in the pharyngeal region are greatly enlarged and packed with sperm, enter the penis bulb separately as narrow tubes with little or no recurvature. Within the bulb they unite to form a broad seminal vesicle. The ejaculatory duct runs from this vesicle to open at the tip of the penis papilla. It is the structure and arrangement of this duct that make this species unusual for it seems that the central core of the penis is eversible, although it should be borne in mind that the following interpretation is based upon only three fully mature specimens.

In the holotype (fig. 7) the central core of the penis is fully everted so as to form a flared extension of the copulatory organ. The flaring of the extension is unequal so that there is an accentuated lip dorsally and to the right, immediately beneath which the ejaculatory duct opens. This terminal part of the duct is surrounded by eosinophil gland cells. The ejaculatory duct and the large seminal vesicle are lined with a tall nucleate epithelium underlain by a prominent layer of irregularly arranged muscle fibres. In both fully mature paratypes the eversion is only partial and involves only the dorsolateral part of the eversible structure. In these specimens the seminal vesicle appears as a large cavity lined with a tall, irregular, and nucleate epithelium. This narrows to a short slim duct which almost immediately widens once more to form the ejaculatory duct proper. The ejaculatory duct is now very wide but it is partially occluded by a large flap from its dorsal (fig. 8) or right lateral (fig. 9) wall. The principal passage of the ejaculatory duct is beneath and to the left of this occlusion and entally, before narrowing prior to entering the seminal vesicle, it receives the secretions of numerous eosinophil glands. It is postulated that this region is homologous with the glandular 'terminal' part of the ejaculatory duct as it appears when fully everted (fig. 7). 


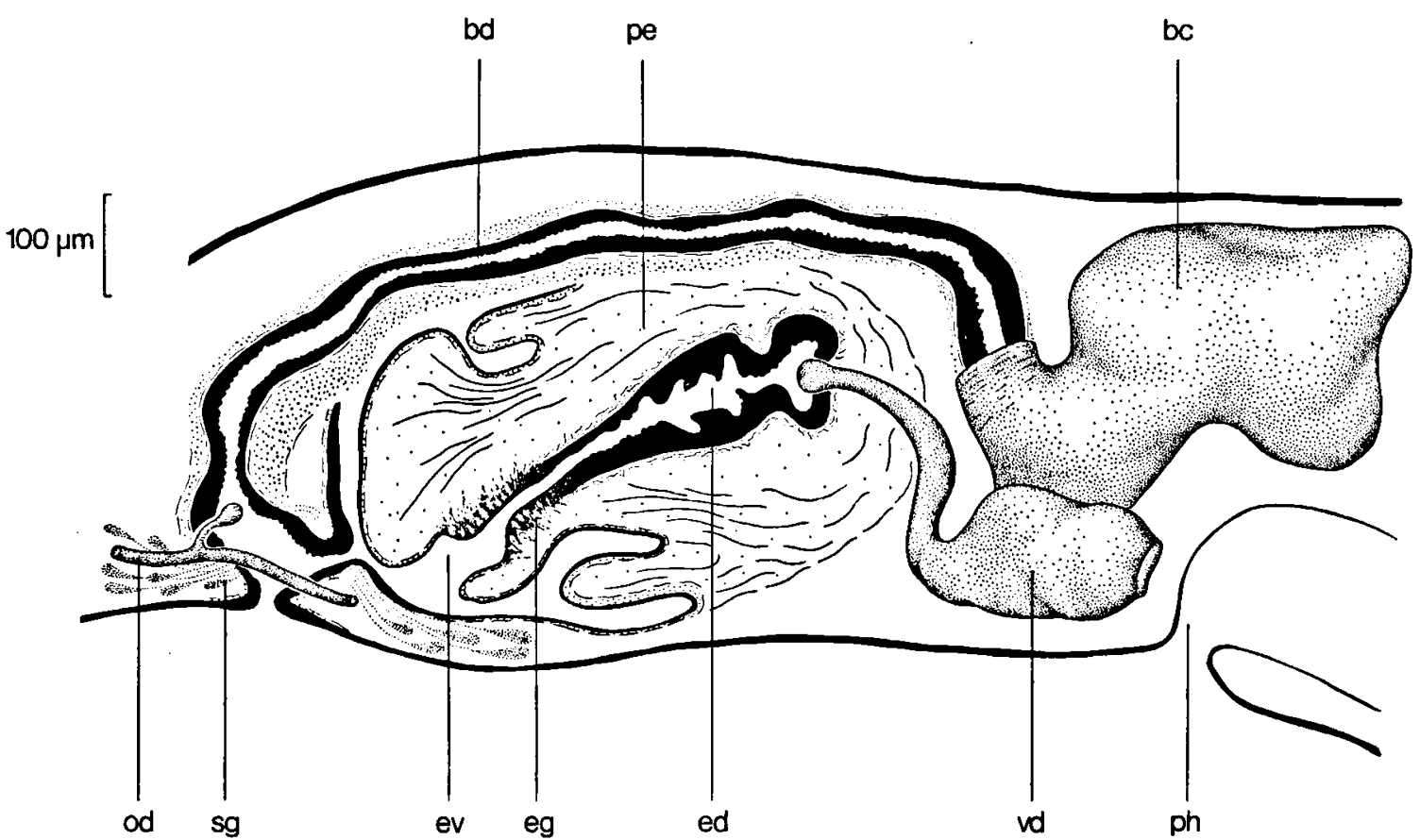

8

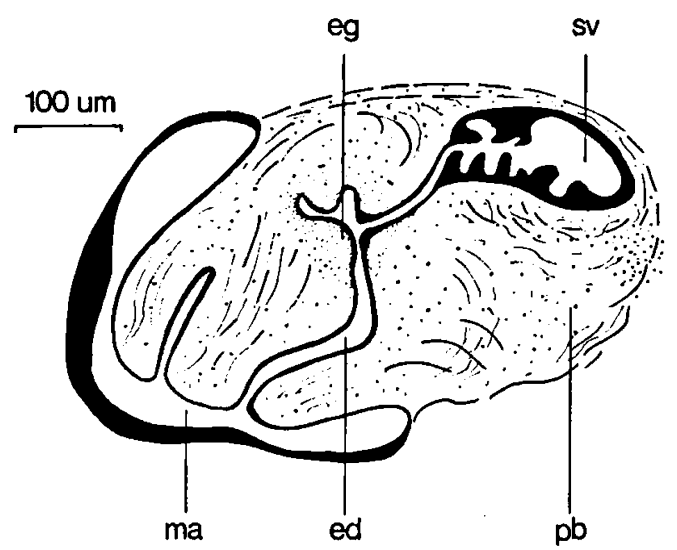

9

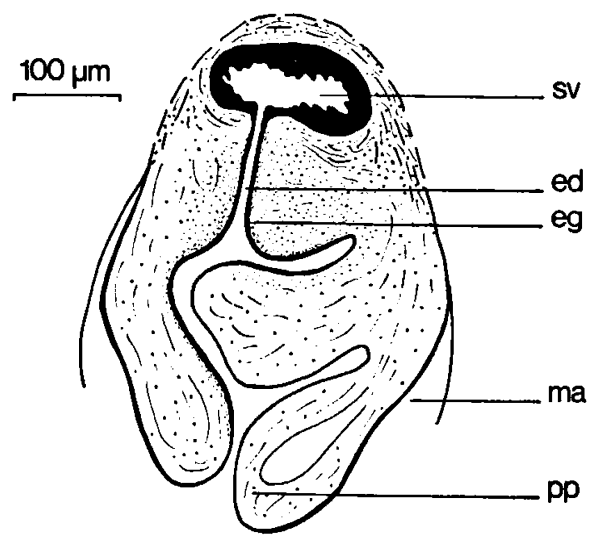

Figs. 7-9. Spathula ochyra sp. nov. 7, sagittal section through the copulatory apparatus of the holotype (K866) viewed from the right side; 8, sagittal section through the penis of a paratype (K867) viewed from the right side; 9, horizontal section through the penis of a paratype (K869) viewed from the dorsal aspect. bc = bursa copulatrix; bd = bursal canal; ed = ejaculatory duct; eg = eosinophil glands; ev = eversible part of ejaculatory duct; ma = male atrium; od = oviduct; $\mathrm{pb}=$ penis bulb; $\mathrm{pe}=$ penis; $\mathrm{ph}=$ pore of pharyngeal pocket; $\mathrm{pp}=$ penis papilla; $\mathrm{sg}=$ shell glands; sv = seminal vesicle; vd $=$ vas deferens.

The testes are very numerous follicles situated in the ventral region of the body and distributed from just behind the ovaries to the level of the bursa copulatrix.

The bursa is a large sac lying between the penis and the pharynx, somewhat to the left of the midline. The bursal canal is a wide duct that curves over the copulatory apparatus and opens into the right side of the atrium above the gonopore. Immediately prior to entering the atrium the 
bursal canal receives the oviducts, and beneath these the openings of the shell glands. The canal is lined with a tall nucleate epithelium that is only conspicuously ciliated entally. The epithelium is overlain by layers of longitudinal and then strong circular muscle fibres which may be reinforced ectally by a few longitudinal fibres. The musculature is thickest on the ventral side of the canal. The bursa itself is largely overlain by a thin layer of encircling fibres extending the circular layer of the canal. One noteworthy feature of the holotype is the agglomeration of sperm in the bursal canal at its junction with the bursa copulatrix. The sperm mass is attached to the epithelium by the heads of the sperm (fig. 10).

The paired ovaries are ventrally situated immediately behind the brain and the oviducts follow the usual course to the copulatory apparatus. Here each branches sending one branch caudad to the posterior vitellaria, and a dorsal branch curving upwards to open into the bursal canal above the zone of the shell glands. The vitellaria extend throughout the body, with a few pre-ovarian follicles, and they are especially extensive in the two fully mature paratypes.

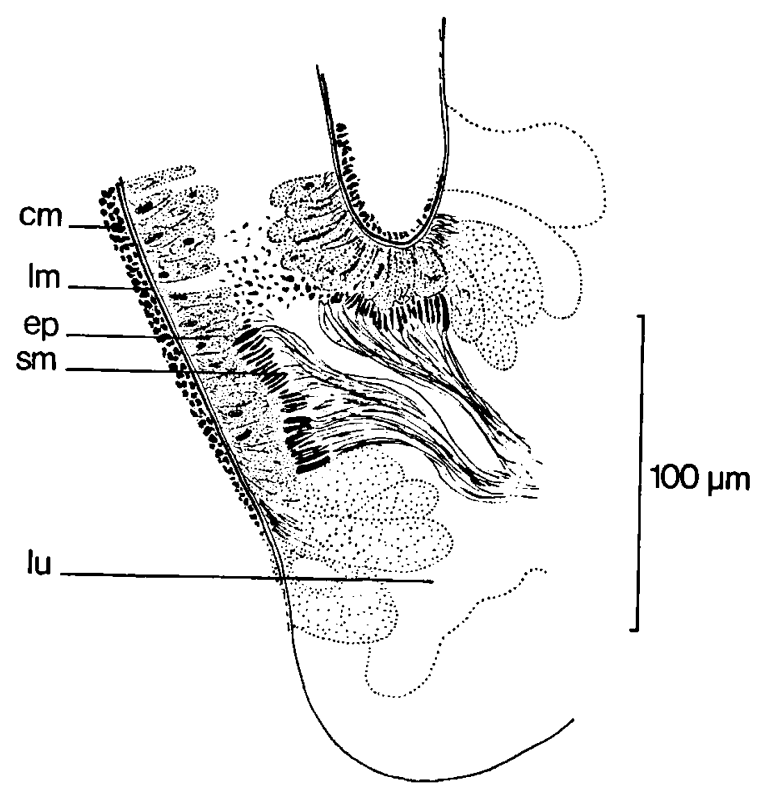

Fig. 10. Spathula ocbyra sp. nov. Sagittal section through the bursa/bursal canal of the holotype. $\mathrm{cm}=$ circular muscle; ep = epithelium; $1 \mathrm{~m}=$ longitudinal muscle; lu = lumen of bursa; $\mathrm{sm}=$ sperm mass.
Diagnosis. - Spatbula ochyra may be readily distinguished from all other species of the genus by its unique penial structure. Externally the new species resembles $S$. fontinalis from New Zealand, the only other species with two pairs of sensory fossae. The latter species, however, has a strong muscle sphincter on the bursal canal that is lacking in the new species, and the position and distribution of the testes are quite different. The preocellar diverticula of the intestine are peculiar to the two Tasmanian Spatbula species described in this paper.

Distribution. - Known only from the type locality which is Arthurs Lake in Tasmania (grid ref. DP 922567). The specimens were collected in Cowpaddock Bay on 29 March 1977 and 22 May 1977 by W. Fulton. The species was found at shallow sites of 3-5 metres on a substrate of coarse black mud, with large amounts of Elodea canadensis, and some other plants, present. In this lake Spatbula ocbyra is less abundant than is Romankenkius bilineatus (Fulton, in litt.).

Etymology. - The specific epithet is from the Greek, ochyros, meaning firm, stout, strong, and is an allusion to both the general appearance of the animal and the appearance of the male copulatory organ.

\section{DISCUSSION OF THE GENUS SPATHULA}

The genus Spatbula originally was erected by Nurse (1950) for two species from New Zealand but it was not accepted by later specialists. Recently, however, Ball (1977a) resurrected, revalidated, and redefined the genus so as to add six new species from New Zealand and southeastern Australia. The geographical distribution of the genus was held to be anomalous because it was unrepresented in Tasmania even though well represented in the mountains of Victoria (Ball, 1977a: 33). With the discovery of the new species from Lake St Clair and Arthurs Lake this biogeographical anomaly is removed.

Both of the new species are unusual for their possession of preocellar diverticula to the anterior ramus of the intestine. This is a primitive feature within the Haploneura as a whole (Meixner, 
1928 ), and whereas it is widespread in the marine species it is rare in the freshwater planarians. A comparable situation within the Australian fauna is to be found only in Eviella bynesae, a primitive retrobursal planarian from Victoria (Ball, 1977b). This species is blind but the anterior ramus extends far forwards from the brain and ends in a series of small diverticula.

The testes are also worthy of comment. In both the Tasmanian species the ventral testes form a continuous zone from just behind the ovaries to the copulatory bursa, a feature shared with $S$. foeni from Victoria (Ball, 1977a: 29-30). This type of distribution, found also in Romankenkius bilineatus, is also characteristic of some species of Neppia, a genus with representatives in South America, South Africa, and New Zealand (Ball, $1974 \mathrm{~b})$. It is of interest, therefore, that our first tentative identification of Spathula ocbyra was that it belonged to this austral genus. The general appearance of the copulatory complex conforms with that of some species of Neppia especially in the large penis, with a wide complex ejaculatory duct and the wide bursal canal with strong musculature that diminishes entally. However the presence of sensory fossae and of branched oviducts preclude the specimens from belonging to Neppia by our criteria (Ball, 1974b) and determine their membership of the genus Spatbula (Ball, 1977a). The phylogenetic and biogeographical relationships of austral planarians have been discussed at length in a number of recent papers (Ball, 1974a, 1974b, 1977a) and need not be repeated here. Nonetheless it is clear that the relationships between these genera will have to be repeatedly re-assessed as new species are discovered and described.

\section{ACKNOWLEDGEMFNTS}

Dr. D. A. Hay (La Trobe University, Melbourne) and Mr. W. Fulton (Inland Fisheries Commission, Hobart, Tasmania) provided the specimens upon which this paper is based. Some of the necessary histological preparation was carried out in the Royal Ontario Museum, Toronto, Canada but most was performed by Greet Vooren in Amsterdam. To all the above we express our thanks. The study was partly supported by Operating Grant A0016 of the National Research Council of Canada.

\section{REFERENCES}

BALL, I. R., 1974a. A contribution to the phylogeny and biogeography of the freshwater triclads (Platyhelminthes, Turbellaria). In: N. W. RISER \& M. P. MORSE eds., Biology of the Turbellaria: 339-401 (McGraw-Hill, New York).

-, 1974b. A new genus of freshwater triclad from Tasmania, with reviews of the related genera Cura and Neppia (Turbellaria, Tricladida). Life Sci. Contr., R. Ont. Mus., 99: 1.48.

- 1977a. A monograph of the genus Spathula (Platyhelminthes, Turbellaria, Tricladida). Aust. J. Zool., Suppl. Ser., 47: 1-43.

,$- 1977 \mathrm{~b}$. A new and primitive retrobursal planarian from Australian fresh waters (Platyhelminthes, Turbellaria, Tricladida). Bijdr. Dierk., 47: 149-155.

- , 1977c. On the phylogenetic classification of aquatic planarians. In: T. G. KARLing \& M. MEINANDER eds., The Alex Luther Centennial Symposium on Turbellaria. Acta zool. Fenn., 154: 21-35.

Leonard, B. V. \& B. V. Timms, 1974. The littoral rock fauna of three highland lakes in Tasmania. Papers Procs. Roy. Soc. Tasmania, 108: 151-156.

MeIXNER, J., 1928. Der Genitalapparat der Tricladen und seine Beziehungen zu ihrer allgemeinen Morphologie, Phylogenie, Ökologie und Verbreitung. Z. Morphol. Oekol. Tiere, 11: 570-612.

NURSE, F. R., 1950. Freshwater triclads new to the fauna of New Zealand. Trans. Roy. Soc. N.Z., 78: 410-417.

Received: 8 March 1979 